EGU2020-10930

https://doi.org/10.5194/egusphere-egu2020-10930

EGU General Assembly 2020

(c) Author(s) 2020. This work is distributed under

the Creative Commons Attribution 4.0 License.

\title{
Role of grain boundary diffusion in H-D exchange in mantle xenoliths
}

Konstantinos Thomaidis and Jannick Ingrin

Univ. Lille, CNRS, INRAE, ENSCL, UMR 8207 - UMET - Unité Matériaux et Transformations, F-59000 Lille, France

(konstantinos.thomaidis@univ-lille.fr)

Water concentration in pyroxenes from mantle xenoliths is frequently used to trace water content in the lithospheric mantle. We do not understand yet how these pyroxenes can preserve a memory of their deep equilibrium during their transport to the surface. In an attempt to evaluate the role of grain boundaries in the exchange of hydrogen between the pyroxenes of the xenoliths and the host magma, we have launched a program of experiments of $\mathrm{H}$ exchange in blocks of mantle xenoliths of centimetre size. The blocks, all from the same xenolith, contain clinopyroxenes, orthopyroxenes and olivine of $\mathrm{mm}$ to sub-millimetre size. We present here the results of a series of $\mathrm{H}-\mathrm{D}$ exchange performed at 600,700 and $900{ }^{\circ} \mathrm{C}$ at room pressure in a deuterium enriched gas. OH-OD profiles recorded by micro-infrared spectroscopy in pyroxenes at the edge of the block are only slightly different from the ones recorded in pyroxenes at the centre of the block. These results show that the diffusion/solubility of hydrogen in grain boundaries is fast enough to equilibrate rapidly the grains at the center of the xenoliths. It proves that in nature the $\delta D$ signature of xenoliths is very likely controlled by the equilibrium with the host magma even in the case of xenoliths with large grain size.

We will also present preliminary results on the role of grain boundary diffusion in the control of hydrogen exchange involving reactions activated at a higher temperature such as the oxidationreduction of iron $\left(1 / 2 \mathrm{H}_{2}+\mathrm{Fe}^{3+}=\mathrm{H}_{\mathrm{i}}^{+}+\mathrm{Fe}^{2+}\right)$ and the formation/destruction of cation vacancies. 